\title{
Editorials
}

\section{The transition to psychosis: risk factors and brain changes}

\author{
STEPHEN J. WOOD ${ }^{1,2}$, MURAT YÜCEL ${ }^{1,3}$, ALISON R. YUNG ${ }^{3}$, GREGOR E. BERGER 3 , \\ DENNIS VELAKOULIS ${ }^{1}$, CHRISTOS PANTELIS ${ }^{1}$
}

\author{
${ }^{`}$ Melbourne Neuropsychiatry Centre, Department of Psychiatry, University of Melbourne, Australia \\ ${ }^{2}$ Brain Research Institute, Melbourne, Australia \\ ${ }^{3}$ ORYGEN Research Centre, Department of Psychiatry, University of Melbourne, Australia
}

\section{INTRODUCTION}

The term psychotic disorder refers to a collection of illnesses that have reality distortion at their centre. Their underlying neurobiology is not well understood, and the mechanisms by which the transition from an 'at-risk' mental state to a clinically defined 'case' occurs less so (Yung et al., 1996). This transitional period has a broad range of possible diagnostic and prognostic categories that include but are not limited to the more traditionally studied groups of disorders such as schizophrenia, schizoaffective and bipolar disorders. Difficulties in researching and intervening at such an early stage of illness include problems in defining "caseness" for a single psychiatric disorder at first onset, the often confusing array of co-morbidity, the instability of diagnoses, the tendency for syndromes to change over time in a proportion of cases and the difficulty to distinguish symptoms from the normal range of experiences. Nonetheless, a bet-

Address for correspondence: Dr. S. Wood, Melbourne Neuropsychiatry Centre, c/o National Neuroscience Facility, 161 Barry Street, Carlton South, VIC 3053 (Australia).

Fax: +61-3-8345.0599

E-mail: stephen.wood@wh.org.au

Declaration of Interest: this research and the clinical research structure of the PACE Clinic was supported by project grants from the National Health \& Medical Research Council (NHMRC: grant ID numbers 970598 and 970391 ), the Victorian Health Promotion Foundation Program grants, the Stanley Foundation and a NARSAD Distinguished Investigator Award to Professor McGorry. This work has also been supported by the Ian Potter Foundation, Woods Family Trust, Jack Brockhoff Foundation, the L.E.W. Carty Trust, the Percy Baxter Charitable Trust and Janssen-Cilag Pharmaceuticals. ter understanding of the neurobiology of the transition period, with the ensuing targets for new treatments (which would not necessarily be anti-schizophrenic), will help to find discriminating variables that predict progression towards more serious diseases.

It is now possible to identify individuals prior to developing a psychotic disorder. For example, using a close in strategy (Bell, 1992) of combining trait (such as family history) and state risk factors (such as current mental state and deterioration in functioning) and/or subthreshold or brief transient psychotic symptoms, our group recruited a cohort of young people thought to be at imminent risk of onset of first episode of psychosis. At one year follow up $35-40 \%$ of these individuals had developed frank psychotic disorder, with over half meeting criteria for schizophrenia (Yung et al., 2003). The ultra high risk (UHR) individuals who subsequently developed a psychotic disorder could therefore be considered to have been incipiently psychotic or prodromal at intake. Investigations of factors that make transition to psychosis more or less likely are continuing in this population. The ability to identify subjects prior to the onset of psychosis enables the examination of a range of variables, including neurocognitive and other putative markers over time (e.g., structural), around the peri-onset phase and prior to the introduction of neuroleptics.

\section{COGNITIVE PREDICTORS OF PSYCHOSIS}

Neuropsychological deficits have been consistently identified at the onset of psychosis (Nopoulos et al., 1994; Saykin et al., 1994; Bilder et al., 2000). Longitudinal studies of first-episode patients also suggest 
that these deficits do not change over time (Rund, 1998; Hoff et al., 1999), implying that neuropsychological deficits are trait related and unlikely to be explained by the effects of medication. However, to date there have been only a few studies that, prior to onset, have examined cognitive measures in patients at risk for the development of psychosis. These studies include the Edinburgh High Risk (EHR, Byme et al., 1999), the New York High Risk (NYHR, Cornblatt \& Keilp, 1994; Erlenmeyer-Kimling et al., 2000), and the Dunedin Multidisciplinary Health and Development (DMHD, Cannon et al., 2002) studies. In the recent reports by the Edinburgh group, slightly lower levels of global cognitive function were identified in a highrisk cohort when compared to a group of matched controls (Byrne et al., 1999). However, none of the subjects had become acutely psychotic at the time of publication; this highlights one of the problems of résearch in high-risk populations, namely, that it remains unclear to what extent neuropsychological deficits identified premorbidly are predictive of the later onset of schizophrenia.

The NYHR has explored this problem by following up a cohort of children into adulthood. The results demonstrated that childhood deficits in attention and short-term memory, measured at around nine years of age, distinguished those who developed a schizophrenia-related psychosis more than 20 years later (Erlenmeyer-Kimling et $a l ., 2000)$. The DMHD study also identified reduced intelligence and receptive language skills in children between the ages of three and nine who later fulfilled criteria for schizophreniform disorder at age 26 years (Cannon et al., 2002). While these studies provide evidence that early neuropsychological deficits may be markers of impending psychotic illness later in life, it is unclear what the specificity of such deficits is for schizophrenia per se. Moreover, their predictive power at this phase of illness is likely to be very weak.

These studies were limited by reliance on genetic vulnerability (in the case of the New York and Edinburgh studies), and the long follow-up period of 25-30 years, with high attrition rates and low transition to psychosis (6$15 \%$ ). More recently, using the ultra high-risk strategy outlined above, we have published reports of the impaired olfactory identification (Brewer et al., 2003) and poor working memory (Wood et al., 2003b) of our high risk population, and their problems with rapid processing of incoming information and its efficient organisation for accurate recall (Brewer et al., in press). Taken together, our findings specifically implicate deficits in prefrontal cortical function prior to transition to psychosis, a conclusion supported by our structural imaging data (Pantelis $e t$ al., 2003a).

\section{IMAGING PREDICTORS OF PSYCHOSIS}

Few brain imaging studies of at-risk patients exist, and neither the early CT studies, nor the MRI studies, have reported the proportion of genetic high-risk subjects who later developed a psychotic illness. It has been shown that such subjects have smaller volumes of the left amygdalahippocampal complex and thalamic nuclei than controls (Lawrie et al., 2001; Keshavan et al., 2002), but we have found that smaller hippocampal volumes are not predictive of later psychosis onset (Phillips et al., 2002). Instead, a survival analysis indicated that it was those subjects with a normal volume who were more likely to become ill. More recent work from our group (Garner et al., unpublished) has shown that an enlarged pituitary volume (presumably due to activation of the hypothalamus-pituitary-adrenal axis) is also predictive of the development of psychosis, and moreover the larger it is, the sooner the transition. In addition, it has been reported in the EHR study that brain activity changes in the parietal lobe may represent early features of the development of psychosis (Whalley et al., 2004). In contrast, morphological measures of other brain regions such as the anterior cingulate (Yücel et al., 2003), and spectroscopic measures from frontal and temporal lobes (Wood et al., 2003a), have failed to demonstrate predictive value. This is despite evidence of the involvement of the anterior cingulate in schizophrenia (Yücel et al., 2002) and spectroscopic changes in relatives of patients with the disorder (Callicott et al., 1998).

While there are even fewer longitudinal imaging studies of high-risk patients, two are noteworthy. In the first, from the EHR study, at-risk subjects as a group did not show greater regional brain volume changes than healthy controls over a 2 year follow-up period, though at-risk subjects with psychotic symptoms showed greater temporal lobe changes than those without (Miller et al., 2002). In the second study, conducted by us (Pantelis et al., 2003a), 75 UHR subjects had a baseline scan of whom 23 developed psychosis and 52 did not. Those who later became psychotic had less grey matter in the right medial temporal, lateral temporal and inferior frontal cortex and in the cingulate cortex bilaterally. Ten subjects who developed psychosis in the follow-up period were rescanned along with 11 who did not. Consistent with the EHR study, grey matter volume reductions in the orbitofrontal and parahippocampal cortices were more pronounced in those who became psychotic suggesting that an active disease process may be taking place in the brain. 


\section{A WAY FORWARD}

Psychotic disorders such as schizophrenia have a putative neurodevelopmental origin (Murray \& Lewis, 1987; Weinberger, 1987), in which subtle differences, which represent an example of this aberrant development, can be found prior to the onset of the disorder. Onset of psychosis typically occurs during adolescence or young adulthood during a period of important brain development (Luna \& Sweeney, 2001). Concurrent with this brain maturation is the emergence of increasingly elaborate cognitive abilities and executive function (Spear, 2000; Andersen, 2003). The prefrontal cortex, with the participation of other brain regions in widely distributed circuits, subserves many aspects of higher-order cognitive function in which there is robust developmental change during adolescence. In schizophrenia and related disorders, a wide range of behavioural and functional imaging studies document impairment in these higherorder cognitive processes (Weinberger et al., 1986; Park \& Holzman, 1992).

We have proposed (Pantelis et al., 2003b) that brain plasticity and the normal maturational trajectory of various functions define the nature and extent of their impairment over the course of the disorder. In particular, we proposed that functions which normally come 'on line' early in life (i.e. during infancy) such as sensory, motor and basic memory functions, when the brain is more adaptable, show fewer deficits at illness onset than functions normally coming on in adolescence such as attention, working memory and executive functions (Pantelis et al., 2001; Wood \& Pantelis, 2001; Pantelis et al., $2003 \mathrm{~b}$ ). These findings also point to a failure of the normal development of the prefrontal cortex as a specific risk factor for the development of psychosis. Support for this model comes from our own (and others) work on the normal development of executive function (McKay et al., 1994; Rebok et al., 1997; Manly et al., 2001; De Luca et $a l ., 2003)$ and is consistent with the available evidence in schizophrenia (Pantelis et al., 1997; Hutton et al., 1998), and also in young people at ultra high-risk for psychosis prior to the onset of illness (Wood et al., 2003b).

What remains unclear from these studies is the way in which the development of prefrontal cortical function might interact with the onset of psychotic behaviour. However, to date there have been no functional imaging studies of this population, limiting our understanding of the brain circuitry that is presumed to be dysfunctional. Given current theorizing regarding the aetiological significance of abnormal maturation of prefrontal cortical networks during late adolescence in the transition to psy- chosis, it is also important to understand dysfunction in a developmental context. Specifically, multivariate analyses of fMRI data, in conjunction with DTI as a cross-correlation between structural and functional maturation of network connections, has the potential to provide a novel understanding of the role of these circuits in the onset of psychotic illnesses.

\section{REFERENCES}

Andersen S. L. (2003). Trajectories of brain development: point of vulnerability or window of opportunity? Neuroscience and Biobehavioural Reviews 27, 3-18.

Bell R. Q. (1992). Multiple-risk cohorts and segmenting risk as solutions to the problem of false positives in risk for the major psychoses. Psychiatry 55(4), 370-381.

Bilder R.M., Goldman R.S., Robinson D., Reiter G., Bell L., Bates J.A., Pappadopulos E., Willson D.F., Alvir J.M., Woerner M.G., Geisler S., Kane J.M. \& Lieberman J.A. (2000). Neuropsychology of firstepisode schizophrenia: Initial characterization and clinical correlates. American Journal of Psychiatry 157, 549-559.

Brewer W.J., Wood S.J., McGorry P.D., Francey S.M., Phillips L.J., Yung A.R., Anderson V., Copolov D., Singh B., Velakoulis D. \& Pantelis C. (2004). Impairment of olfactory identification ability in individuals at ultra high-risk for psychosis who later develop schizophrenia. American Journal of Psychiatry 160, 1790-1794.

Brewer W.J., Francey S.M., Wood S.J., Jackson H.J., Pantelis C., Phillips L.J., Yung A.R., Anderson V. \& McGorry P.D. (in press). Memory impairments identified in people at ultra high-risk for psychosis who later develop first episode psychosis. American Journal of Psychiatry

Byrne M., Hodges A., Grant E., Owens D.G. C. \& Johnstone E.C. (1999). Neuropsychological assessment of young people at high genetic risk for developing schizophrenia compared with controls: preliminary findings of the Edinburgh High Risk Study (EHRS). Psychological Medicine 29, 1161-1173.

Callicott J.H., Egan M., Bertolino A., Mattay V.S., Langheim F.J.P., Frank J.A. \& Weinberger D.R. (1998). Hippocampal N-acetyl aspartate in unaffected siblings of patients with schizophrenia: A possible intermediate neurobiological phenotype. Biological Psychiatry 44, 941-950.

Cannon M., Caspi A., Moffitt T.E., Harrington H., Taylor A., Murray R.M. \& Poulton R. (2002): Evidence for early-childhood, pandevelopmental impairment specific to schizophreniform disorder: Results from a longitudinal birth cohort. Archives of General Psychiatry 59, 449-456.

Cornblatt B. \& Keilp J. G. (1994). Impaired attention, genetics, and the pathophysiology of schizophrenia. Schizophrenia Bulletin 20,3146.

De Luca C. R., Wood S.J., Anderson V., Buchanan J.-A., Proffitt T., Mahony K. \& Pantelis C. (2003). Normative data from the CANTAB. I: Development of executive function over the lifespan. Journal of Clinical and Experimental Neuropsychology 25, 242254.

Erlenmeyer-Kimling L., Rock D., Roberts S.A., Janal M., Kestenbaum C., Cornblatt B., Adamo U.H. \& Gottesman I.I. (2000). Attention, memory, and motor skills as childhood predictors of schizophreniarelated psychoses: The New York high-risk project. American Journal of Psychiatry 157, 1416-1422.

Hoff A.L., Sakuma M., Wieneke M., Horon R., Kushner M. \& DeLisi L.E. (1999). Longitudinal neuropsychological follow-up study of patients with first-episode schizophrenia. American Journal of Psychiatry 156, 1336-1341. 
Hutton S.B., Puri B.K., Duncan L.-J., Robbins T.W., Barnes T.R.E. \& Joyce E.M. (1998). Executive function in first-episode schizophrenia. Psychological Medicine 28, 463-473.

Keshavan M.S., Dick E.L., Mankowski I., Harenski K., Montrose D.M., Diwadkar V.A. \& DeBellis M. (2002). Decreased left amygdala and hippocampal volumes in young offspring at risk for schizophrenia. Schizophrenia Research 58, 173-183.

Lawrie S.M., Whalley H., Abukmeil S.S., Kestelman J.N., Donnelly L., Miller P., Best J.J.K., Cunningham Owens D.G. \& Johnstone E.C. (2001). Brain structure, genetic liability, and psychotic symptoms in subjects at high risk of developing schizophrenia. Biological Psychiatry 49, 811-823.

Luna B. \& Sweeney J.A. (2001). Studies of brain and cognitive maturation through childhood and adolescence: A strategy for testing neurodevelopmental hypotheses. Schizophrenia Bulletin 27(3), 443455.

Manly T., Anderson V., Nimmo-Smith I., Turner A., Watson P. \& Robertson I. (2001). The differential assessment of children's attention: The Test of Everyday Attention for Children (TEA-Ch). Normative sample and ADHD performance. Journal of Child Psychology and Psychiatry 42, 1065-1087.

McKay K., Halperin J., Schwartz S. \& Sharma V. (1994). Developmental analysis of three aspects of information processing: Sustained attention, selective attention and response organization Development Neuropsychology 10, 121-132.

Miller P.M., Lawrie S.M., Byrne M., Cosway R. \& Johnstone E.C. (2002). Self-rated schizotypal cognitions, psychotic symptoms and the onset of schizophrenia in young people at high risk of schizophrenia. Acta Psychiatrica Scandanavica 105, 341-345.

Murray R.M. \& Lewis S.W. (1987). Is schizophrenia a neurodevelopmental disorder? British Medical Journal 295, 681-682.

Nopoulos P., Flashman L.A., Flaum M., Arndt S. \& Andreasen N.C. (1994). Stability of cognitive functioning early in the course of schizophrenia. Schizophrenia Research 14, 29-37.

Pantelis C., Barnes T.R.E., Nelson H.E., Tanner S., Weatherley L., Owen A.M. \& Robbins T.W. (1997). Frontal-striatal cognitive deficits in patients with chronic schizophrenia. Brain 120, 1823-1843.

Pantelis C., Yücel M., Wood S.J., McGorry P.D. \& Velakoulis D. (2001). The timing and functional consequences of structural brain abnormalities in schizophrenia. NeuroScience News 4, 36-46.

Pantelis C., Velakoulis D., McGorry P.D., Wood S.J., Suckling J., Phillips L.J., Yung A.R., Bullmore E.T., Brewer W.J., Soulsby B., Desmond P. \& McGuire P.K. (2003a). Neuroanatomical abnormalities before and after onset of psychosis: a cross-sectional and longitudinal MRI study. Lancet 361, 281-288.

Pantelis C., Yücel M., Wood S.J., McGorry P.D. \& Velakoulis D. (2003b). Early and late neurodevelopmental disturbances in schizophrenia and their functional consequences. Australian and New Zealand Journal of Psychiatry 37, 399-406.

Park S. \& Holzman P.S. (1992). Schizophrenics show spatial working memory deficits. Archives of General Psychiatry 49, 975-982.

Phillips L.J., Velakoulis D., Pantelis C., Wood S.J., Yuen H.P., Yung A.R., Desmond P., Brewer W.J. \& McGorry P.D. (2002). Nonreduction in hippocampal volume is associated with risk for psy- chosis. Schizophrenia Research 58, 145-158.

Rebok G., Smith C., Pascualvaca D., Mirsky A., Anthony B. \& Kellam S. (1997). Developmental changes in attentional performance in urban children from eight to thirteen years. Child Neuropsychology 3, 47-60.

Rund B.R. (1998). A review of longitudinal studies of cognitive functions in schizophrenia patients. Schizophrenia Bulletin 24(3), 425435.

Saykin A.J., Shtasel D.L., Gur R.E., Kester D.B., Mozley L.H., Stafiniak P. \& Gur R.C. (1994). Neuropsychological deficits in neuroleptic naive patients with first-episode schizophrenia. Archives of General Psychiatry 51, 124-131.

Spear L.P. (2000). The adolescent brain and age-related behavioural manifestation. Neuroscience and Biobehavioural Reviews 24, 417 463.

Weinberger D.R. (1987). Implications of normal brain development for the pathogenesis of schizophrenia. Archives of General Psychiatry $44,660-669$.

Weinberger D.R., Berman K.F. \& Zec R.F. (1986). Physiologic dysfunction of dorsolateral prefrontal cortex in schizophrenia I. Regional cerebral blood flow evidence. Archives of General Psychiatry 43, 114-124.

Whalley H., Simonotto E., Flett S., Marshall I., Ebmeier K.P., Owens D.G.C., Goddard N.H., Johnstone E.C. \& Lawrie S.M. (2004). fMRI correlates of state and trait effects in subjects at genetically enhanced risk of schizophrenia. Brain 127, 478-490.

Wood S.J. \& Pantelis C. (2001). Does a neurodevelopmental lesion involving the hippocampus explain memory dysfunction in schizophrenia? Zeitschrift für Neuropsychologie 12(1), 61-67.

Wood S.J., Berger G.E., Velakoulis D., Phillips L.J., McGorry P.D., Yung A.R., Desmond P. \& Pantelis C. (2003a). Proton magnetic resonance spectroscopy in first episode psychosis and ultra high-risk individuals. Schizophrenia Bulletin 29, 831-844.

Wood S.J., Pantelis C., Proffitt T., Phillips L.J., Stuart G.W., Buchanan J.-A., Mahony K., Brewer W.J., Smith D. \& McGorry P.D. (2003b). Spatial working memory ability is a marker of risk-for-psychosis. Psychological Medicine 33, 1239-1247.

Yücel M., Stuart G.W., Maruff P., Wood S.J., Savage G., Smith D., Crowe S.F., Copolov D., Velakoulis D. \& Pantelis C. (2002). Paracingulate morphologic differences in males with established schizophrenia: A magnetic resonance imaging morphometric study. Biological Psychiatry 52, 15-23.

Yücel M., Wood S.J., Phillips L.J., Stuart G.W., Smith D., Yung A.R., Velakoulis D., McGorry P.D. \& Pantelis C. (2003). Morphological anomalies of the anterior cingulate cortex in young individuals at ultra high-risk of developing a psychotic illness. British Journal of Psychiatry 182, 518-524.

Yung A.R., McGorry P.D., McFarlane C.A., Jackson H.J., Patton G.C. \& Rakkar A. (1996). Monitoring and care of young people at incipient risk of psychosis. Schizophrenia Bulletin 22, 283-303.

Yung A.R., Phillips L.J., Yuen H.P., Francey S., McFarlane C.A., Hallgren M.A. \& McGorry P.D. (2003). Psychosis prediction: 12 month follow-up of a high risk ('prodromal') group. Schizophrenia Research 60(1), 21-32. 